\title{
sciendo
}

\section{Pragmatism. Propositional Priority and the Organic Model of Propositional Individuation}

\author{
María J. Frápolli \\ University College London
}

Neftalí Villanueva

University of Granada

BIBLID [0873-626X (2016) 43; pp. 203-217]

\begin{abstract}
We identify two senses of 'pragmatics' and related terms that give rise to two different methods of propositional individuation. The first one is the contextualist approach that essentially acknowledges contextual information to take part in the determination of what is said by the utterance of a sentence. In this sense, Pragmatics relies on the Principle of Compositionality and interprets propositions as structured entities. It epitomises the Building-block Model of Propositional Individuation. The general approach that makes what the agents do the grounding level of philosophical and linguistic analysis characterizes the second sense, Pragmatism. It finds its clearest expression in Peirce's Pragmatist Maxim, and it relies on (a particular interpretation of) the Fregean Principle of Context, and supports a view of propositions as unstructured entities. This is the Organic Model of Propositional Individuation. There is a test, the Analytic Equivalence Test, that tells apart the two models. According to it, the answer to the question whether a theory makes room for different but analytically equivalent propositions determines the model the theory belongs in. A positive answer classifies the theory as belonging to the building-block model; a negative answer allocates the theory within the organic model.
\end{abstract}

\section{Keywords}

Building-block model, compositionality, expressivism, Frege, relativism. 


\section{Two models}

Pragmatism is a label that arguably applies to two distinguishable, even if related, subjects. A pragmatist approach to the study of language is one that makes room for contextual factors in the individuation of what is said. Contextualist positions range from the minimal context-dependence of indexical contextualism, where the effect of context is restricted to the function of filling in the gaps in the linguistic structure, to the radical presence of contextual information in truth conditional pragmatics, where context affects each level of meaning. The relevant question for the pragmatic approach to the study of language is how and to which extent constant information related to the linguistic meaning of expressions, on the one hand, and variable information retrieved from the context of use, on the other, get intertwined in the individuation of what an agent says when she utters a particular sentence. We usually call the discipline that explores this question and in which philosophers and linguists work hand in hand 'pragmatics'.

A different use of the label serves to characterize those kinds of general philosophies that make of practices, i.e. of what agents do, the focus of their interest and the beginning of their inquiries. If it is the philosophy of language what is at stake, pragmatism in this second sense amounts to the claim that the minimal units relevant in communicative exchanges are actions of some kind. Actions are thus the primary bearers of semantic and pragmatic properties. The American philosophers Peirce, Sellars, Quine, Putnam, and Brandom, among others, and the European philosophers Ramsey, Haack and, we will argue, Frege, all share this take on philosophy. Pragmatism narrows down to Peirce's Pragmatist Maxim:

Consider what effects, that might conceivably have practical bearings, we conceive the object of our conception to have. Then, our conception of these effects is the whole of our conception of the object (Peirce 1878: 293)

In more colloquial terms, pragmatism implies that there cannot be distinctions without practical differences. If two sentences produce the same effect, they express the same content even if they differ in structure and lexical ingredients. 
Surely, there are patent similarities between the two senses of 'pragmatics'/'pragmatism' so far distinguished, similarities that speak for the convenience of maintaining the label 'pragmatism' to cover the two approaches. Our aim in this paper will be, nevertheless, to pay attention to the differences. We will argue that each type of pragmatism harbours a different model of content individuation. The first kind lends support to the building-block model of propositional individuation whereas the second kind relies on what we have dubbed somewhere else the 'organic model' (Frápolli and Villanueva 2015). Even if context intervenes in the individuation of content, the building-block model confers a relevant place to the Principle of Compositionality, which systematically gives rise to a conception of propositions as structured entities. The organic model essentially puts context first and defines propositions by their theoretical and practical implications. The Fregean Principle of Context is the backbone of the organic model, in which sub-propositional parts of the content of a judgment can only be reached at once complete propositional acts have been produced. In this model, propositions are non-structured entities to which a structure can be attributed only as an effect of analysis. In this model, the structure is not the germ of propositions but a way of explaining their inferential potential. The building-block and the organic models elicit radically different conceptions of propositions and of the role of context in their individuation conditions.

\section{The building-block model and the principle of composi- tionality}

Context-dependence is considered as a phenomenon that characterizes human linguistic practices almost all the way through the spectrum of different theories of meaning. Determining the content of our meaningful communicative exchanges seems to require, at one level or another, recruiting some information from the context. Isidora Stojanovic's notion of what is said (Stojanovic 2007) might be among the few attempts to characterize meaning in a fully contextindependent manner. For the most part, the lexical meaning of the symbols involved in our utterances is taken to fall short of the kind 
of complex meaning that might be of any interest for the theorist, the kind of meaning that can get you into trouble, the kind of meaning for which you have to be accountable.

Even if the presence of indexical pronouns - understood as expressions whose content changes from context to context - is taken on board by almost every theory of meaning, it is not uncommon to hold wildly different views with respect to how context-dependence, in more general terms, should be theoretically accommodated, and how many linguistic phenomena seem to be context-dependent. Thus, there are those who treat context-dependence, except for indexicality, to belong to the realm of the semantically inert. This strategy is the hallmark of Cappelen and Lepore's (2005) "speech act pluralism", but it is also present in pragmatic explanations of opacity (see Salmon 1986, but also Saul 1998), presuppositional explanations of the context-dependence of knowledge attributions (López 2015), and on every attempt to cash out the impact of conative attitudes on our moral and epistemic judgments in terms of implicatures - being those conventional (Copp 2001, 2009), particularized conversational (Finaly 2005), or generalized conversational implicatures (Strandberg 2012, Grajner 2014). Others refuse to accept that pragmatic processes cannot successfully affect what is said. Some restrict the quest for semantically relevant information to the context of use (cfr. Recanati 2010, Carston 2002), while others highlight the importance of the context of assessment in the explanation of our truth-intuitions (MacFarlane 2014).

All these kinds of contextualism share a common feature, though. They conceive the process of content individuation as a step-by-step mechanism that takes us from the most basic semantic information at the level of the lexical meaning of subsentential expressions to the highest nuances of meaning and propositional content. This is done, first, with the aid of the principle of compositionality, according to which the meaning of complex expressions is a function of the meanings of its parts, and the way in which they are combined. Once semantic composition is completed, other inferential processes can be triggered, where extra propositional content is conveyed once what is said is put together with several general conversational principles. Therefore, what is said, the basic propositional content of our assertions is a direct result of composition. Propositions are individuated 
by paying attention to their parts, and then implicatures are derived from these. Every level of meaning is the result of a growing process that starts from the most elementary components and proceeds orderly, hence the name — the 'building block model'.

3 The organic model and the principle of propositional priority

Truths and some kind of sequences of truths, i.e. propositions and inferences, were Frege's first concern (Frege 1879: 5). Frege understood propositions as the contents of judgments and assertions: "to recognize something as true is to make a judgment, and to give expression to a judgment is to make an assertion" (Logic 1879-1891: 2). Judgments and assertions are actions that require a context. According to Frege, there are two ways in which judgments can differ: (i) There might be the case that from them, perhaps with the aid of some other premises, the same set of consequences follows; (ii) it also might occur that the sets of their consequences do not coincide even if the added premises were the same. The view in Begriffsschrift (1879) dictates that in the first situation there is a single content that the judgments share. In the second situation, the judgments express different propositions. The inferentialist methodology of content individuation introduced by Frege in 1879 places his proposal within the organic model and permits to consider his take on the analysis of propositions and inferences as pragmatic. Contents are individuated by their connections to other contents, disregarding the inner structure that we might attribute to them. This is clear in 1879:

Let us assume that the circumstance that hydrogen is lighter than carbon dioxide is expressed in our formula language, we can then replace the sign for hydrogen by the sign for oxygen or that for nitrogen. This changes the meaning in such a way that 'oxygen' or 'nitrogen' enters into the relations in which 'hydrogen' stood before. If we imagine that an expression can thus be altered, it decomposes into a stable component, representing the totality of relations, and the sign, regarded as replaceable by others, that denotes the object standing in these relations. The former component I call a function, the latter its argument. The distinction has nothing to do with the conceptual content; it comes about only because we view the expression in a particular way (our italics) (Frege 1879: 22). 
The organic model follows the Fregean principle of context: "never to ask for the meaning of a word in isolation, but only in the context of a proposition" (1884: xxii). This principle, together with the inferentialist methodology introduced in 1879, defines the semantic model of propositional individuation. The principle of context, as it happens with the principle of compositionality, is general enough as to apply to different aspects of meaning. If applied to the linguistic meaning of sentences and its subsentential parts it makes a point that has become the core of truth-conditional pragmatics. We call this way of understanding Frege's insight the 'principle of meaning modulation':

Principle of Meaning Modulation: The meanings of the subsentential parts of a sentence adapt to each other into a coherent whole.

The following text is an explicit statement of the principle:

In context the meaning of words is adjusted or 'modulated' so as to fit what is being talked about. Sense modulation is essential to speech, because we use a (more or less) fixed stock of lexemes to talk about an indefinite variety of things, situations and experiences. Through the interaction between the context-independent meanings of our words and the particulars of the situation talked about, contextualized, modulated senses emerge, appropriate to the situation at hand. The meaning of a word can thus be made contextually more specific, or it may, on the contrary, be loosened and suitably extended, as in metaphor. It may also undergo 'semantic transfer', etc.

According to many authors among those who have studied the phenomenon, modulation is the process whereby the meaning of a given word is affected by the meanings of other words in the same sentence. Thus the meaning of the adjective 'light' is affected by the meaning of the noun it modifies: a light lunch is not light in quite the same sense in which a piece of luggage is said to be light. According to Jonathan Cohen, this is one of the big differences between natural language and formal languages: "artificial languages satisfy an insulationalist account whereas natural languages require an interactionist one" (Recanati 2004: 131-2).

A different reading is what we call the 'principle of propositional priority': 
Principle of Propositional Priority: Propositions, and not concepts, are the primary bearers of logical, semantic, and pragmatic properties.

The principle of propositional priority encloses a central pragmatist intuition - that analysis only takes off once the contents of speech acts become available. Wittgenstein follows this line and Brandom develops it: "sentences are the kind of expression whose freestanding utterance [...] has the pragmatic significance of performing a speech act" (Brandom 2001: 125). "Without expressions of this category", Brandom went on, "there can be no speech acts of any kind, and hence no specifically linguistic practice" (loc.cit).

Frege uses the organic procedure to individuate the contents expressed by ordinary first-level sentences, i.e. those contents that Ramsey calls beliefs of the 'primary sort' (Ramsey 1929: 146) and Boole and Frege 'primary propositions' (Frege 1881: 14). Nevertheless, the organic model earns its living in the analysis of contents in which higher-order notions occur essentially. Let us consider two examples, the Fregean definition of number in Foundations (1884), and his claims about the composition of thoughts in "Compound Thoughts" (1923-6), examples that practically enclose Frege's whole life.

In Foundations, in order to achieve a logically adequate definition of number Frege proposed to focus on the basic propositions in which numbers occurred: "It should throw some light on the matter to consider number in the context of a judgment which brings its basic use" (1884 § 46: 59). A logically adequate definition is one that gives the right consequences and that allows an explanation of the inferential connections among propositions of a certain kind. He reviewed former approaches to numbers as aggregations of units and understood that only by looking at the role that numerical expressions play in sentences likes 'four horses draw the Kaiser's carriage' numbers could be characterized. Frege's (1884) is thus the principle of context put to work.

"Compound Thoughts" (1923-26) is a further conspicuous example of the organic model, which insists on the idea that different sentences with different structures can possess the same content. Logical constants, which are unsaturated notions, serve to form complex thoughts out of simpler ones. It is essential to keep in mind that the 
results of operating on sets of thoughts by means of logical constants can be rendered into natural and logical languages via sentences with different ingredients. Any instance of the schema ' $(A \& A)$ ' expresses the same thought expressed by the corresponding instance of ' $A$ ' (Frege 1923-6: 393, n. 21). 'A \& A' expresses the same content as 'A or $A$ ', under any consistent substitution of their parts. Any instance of the schema 'Not [(not $A) \&(\operatorname{not} B)]$ ' expresses the same thought as the corresponding instances of 'Not [Neither $A$ not $B$ ]' and the corresponding instances of ' $A$ or $B$ ' (Frege 1923-6: 396).

The organic model thus implies that propositions do not mirror the sentences that we use to express them. Language makes thoughts perceptible, Frege claimed once and again (Frege 1918-19a: 354, 1923: 259) but the relation between sentences and propositions is not one-one. This is precisely one of the lessons of his take on logic and semantics, that grammar is not a reliable clue to content. This intuition suggests a test, the "analytic-equivalence test", which helps make the divide between the building-block model and the organic model, since according to the former but not to the latter there can be necessarily equivalent propositions that are nevertheless different. From the language viewpoint the test shows that two synonymous sentences necessarily express the same proposition in the organic model and might express distinct propositions according to the building-block method of content individuation. We will go back to the test and its consequences in the last section.

In summary, the Fregean principle of propositional priority, which gives preeminence to the whole over its virtual parts, introduces a way of individuating propositional contents that makes an idiosyncratic use of context, a use that cannot be accommodated in any of the contemporary positions that explain the effect of contextual factors in what is said as an issue of filling in the gaps in a structure. The Fregean organic model and the building-block model that serves as a background for contextualist theories stand in sharp contrast with profound philosophical consequences. 


\section{Expressivism and the organic model}

Expressivism belongs within the organic-model; contextualism and relativism align with the building-block model. Even if there might be aspects of those general approaches that can superficially resemble each other, there are deep dissimilarities between them that should not be overlooked.

Both general approaches evolve from different starting points that reveal contrasting theoretical concerns. Contextualism centers in the composition of what is said, in the process of the propositional constitution; expressivism mainly focuses on the behavior of complex contents that essentially incorporate higher-order concepts. Frege, let us be reminded, introduces his principle of propositional priority to deal with numerical concepts, which in his view are quantifiers. Modern expressivists attempt to explain the behavior in context of notions such as truth, belief, knowledge, good, self, and others of a similar kind, which arguably are higher-order functions whose arguments are $\mathrm{n}$-adic predicables $(\mathrm{n} \geq 0)$. Examples of higherorder notions at work are the following:

(1) Nef knows that María José lives in London

(2) Nef believes that María José lives in London

(3) Joan or Victoria will give a talk tomorrow

(4) Joan and Victoria will give a talk tomorrow

(5) Cheating on your husband is good

(6) Cheating on your husband is bad.

The expressivist stance to sentences of this kind consists in changing the classical question on the meaning of terms and concepts and looking instead at the general import of the speech act in which they are used. What does the speaker do by uttering any of them? Which kind of commitments does she acquire? In the organic model, identity of commitments and entitlements means identity of contents. Diversity of commitments and entitlements means diversity of contents. Let us now consider the differences in import of the pair of 
sentences listed above from the organic point of view. The epistemic notions of knowledge and belief are different because their use has different practical consequences, consequences that affect the behavior of the speaker and also that of the attributor of the attitudes.

By uttering (1), a speaker endorses the content that María José lives in London, i.e. the attributor of knowledge to a third person endorses himself the attributed content. In contrast, the attributor of belief doesn't take on her a similar duty. Uttering (2) is compatible with the utterer thinking that Nef is wrong. If you think that cheating on your husband is wrong, your behavior (linguistic and non-linguistic) ought to be congruent with you belief on pain of irrationality. Conjunction and disjunction are different notions because sentences such as (4) above imply any one of their conjuncts but sentences such as (3), 'Joan or Victoria will give a talk', do not imply any of their disjuncts. Believing that cheating on your husband is wrong commits the believer with a particular course of action, etc. And these consequences, these courses of actions, exhaust the meaning of the higher-order notions involved. That the meaning of higher-order notions is not a building-block but has to be identified by looking at the consequences, theoretical and practical, of the speech acts in which they occur is a central claim of all expressivist approaches and determines the semantic core of the organic model.

A standard criticism against the inferentialist approach within which the organic model belongs is the charge of semantic holism that requires logical omniscience. The criticism rests on a poor understanding of what a pragmatist background means. The way in which expressivism and inferentialism individuate content is essentially context-dependent, avoiding thus the standard analytic practice of looking for general necessary and sufficient conditions. Not every inferential connection contributes to what is said and precise boundaries cannot be established a priori. The agents involved in communicative actions have to be aware of the inferential connections relevant to the individuation of the contents put forward. Logical omniscience might be a problem for the semantics of omniscient agents. Pragmatism is a semantics for agents who are essentially earthbound. 


\section{The analytic-equivalence test}

A crucial difference between the building-block model and the organic model resides on the status that they concede to analytic equivalence. If what is said is a function of the meanings of its parts, and the way they are combined, as the building-block model maintains, then there is a chance that we might find analytically equivalent, yet different, propositions. If, on the other hand, the principle of propositional priority is taken as the cornerstone of our theory of meaning, then analytically equivalent sentences, those that happen to have the same inferential import, can only be different ways to express the same proposition. Within the organic model, there are no distinct analytically equivalent propositions. MacFarlane's discussion concerning expressivism (MacFarlane 2014: 174) already makes use of this idea - that relativism, as a representative of the building block model, is committed with the possibility of propositions being different but analytically equivalent, while expressivism needs to reject this possibility.

Benson Mates' somewhat convoluted cases (Mates 1952) were designed to show that no two different expressions could ever be truly synonymous. For every pair of expressions $s$ and $s^{\prime}$, no matter how close their meanings appear to be, it was possible to generate a couple of sentences $S$ and $S^{\prime}$ with different truth conditions, even if $S^{\prime}$ was the result of merely exchanging $s$ for $s^{\prime}$ in $S$. This seems to favor the building-block model, where the meaning of the whole comes as a function of the meaning of the parts. Different ingredients lead to different truth-conditions.

(1a) Nobody doubts that, whoever believes that ophthalmologists are ophthalmologists, believes that ophthalmologists are ophthalmologists

(1b) Nobody doubts that, whoever believes that ophthalmologists are ophthalmologists, believes that ophthalmologists are oculists.

(1a) is intuitively judged to be true, while (1b) is intuitively judged to be false, and this is only to be expected, provided that (1a) and (1b) have different semantic material. If there were synonymous 
expressions, on the contrary, the mere substitution of one for the other should not alter the inferential potential of the whole, its truth conditions. This looks like a prima facie confirmation of the insight that lies behind the building-block model.

In the Fregean examples above, the analyses of conjunction, disjunction, and negation rest on the assumption that their content is individuated by their inferential import. It is also assumed that some subsets of them are definable in terms of some other subsets. If 'Not [(not $A)$ and (not $B)]$ ' always expresses the same thought as the corresponding instances of 'Not [Neither $A$ not $B$ ]' and the corresponding instances of ' $A$ or $B$ ' (Frege 1923-6: 396), Mates' insight to the effect that no substitution preserves truth-conditions in all contexts is challenged. In these examples, different ingredients do not lead to different propositions. Compare (1a/1b) with $(2 \mathrm{a} / 2 \mathrm{~b})$ :

(2a) Nobody doubts that, whoever believes that politicians are corrupt, believes that politicians are corrupt,

(2b) Nobody doubts that, whoever believes that politicians are corrupt, believes that it is not the case that politicians are not corrupt,

There is a clear disanalogy here. The substitution of 'politicians are corrupt' for 'it is not the case that politicians are not corrupt' does not yield an intuitive change in truth-conditions. Even if at first sight, a speaker might think that there is a difference in truth-value between (2a) and (2b), this impression should change on closer examination. Unlike what happens with (1a) and (1b), mastery of language precludes the failure on seeing that (2a) and (2b) express the same content. Lexical ignorance does not necessarily means linguistic incompetence, logical ignorance necessarily does. The explanation of the identity of truth-conditions of (2a) and (2b) rests on the analytical connection between 'politicians are corrupt' and 'it is not the case that politicians are not corrupt'. These sentences are analytically equivalent, and it makes no sense to believe one but not the other, if the rationality of the believer is not going to be questioned. Different ingredients here do not amount to any difference in meaning. 


\title{
Conclusion
}

Both models have strengths and weaknesses and at the level of firstorder contents the two parties propose rather similar accounts. Nevertheless, when functions of propositions are involved, the analyticequivalence test settles the issue for the organic model. Only the organic model agrees with the speakers' intuitions and thus it is the only one appropriate for the analysis of higher-order functions, in general, and functions of propositions, in particular. We might reject that the speakers' intuition plays any role in the analysis of meaning, as the proponents of the various error theories do, but this move would take the study of language away from the game of science. We chose the empirical path by assuming that semantic hypotheses on the behavior of functions of propositions were a posteriori (Frápolli and Villanueva 2012). The analytic-equivalence test adjudicates between the principle of compositionality and the principle of propositional priority and confirms that, at least when higher-order concepts are at stake, expressivism is the correct approach. ${ }^{1}$

\author{
María J. Frápolli \\ Department of Philosophy, University College London \\ 19 Gordon Square, London, WC1H 0AG \\ mjfrapolli@ucl.ac.uk \\ Neftalí Villanueva \\ Department of Philosophy I. University of Granada \\ Campus Cartuja, s/n, 18071 Granada \\ nef@ugr.es
}

\footnotetext{
${ }^{1}$ This Project has received funding from the European Union's Horizon 2020 research and innovation programme under the Marie Skłodowska-Curie Grant Agreement No. 653056. It has also received funding from the Spanish Ministerio de Economía y Competitividad, Proyecto FFI2013-44836-P, Expresivismo, Naturalismo y Normatividad, and from the University of Granada, Proyecto Expresivismo Doxástico. We are deeply grateful to the organizers of the first Blasco Disputatio (Valencia, 25th-26th October 2015), to the organizers of the Granada permanent seminar Trabajos en Construcción (27th October 2015), and to the audiences of both events for encouraging comments and criticisms on an earlier version of this paper.
} 


\section{References}

Bar-On, D. 2004. Speaking My Mind. New York: Oxford University Press. Brandom, R. 2001. Articulating Reasons. An Introduction to Inferentialism. Cambridge, Mass.: Harvard University Press.

Cappelen, H. and Lepore, E. 2005. Insenstive Semantics. Basil Blackwell.

Carston, R. 2002. Thoughts and Utterences. The Pragmatics of Explicit Communication. Blackwell Publishers Ltd.

Chrisman, Matthew. 2007. From epistemic contextualism to epistemic expressivism. Philosophical Studies 135: 225-254.

Copp, David. 2001. Realist-expressivism: a neglected option for moral realism. Social Philosophy and Policy 18: 1-43.

Copp, D. (2009). Realist-expressivism and conventional implicature. In Oxford studies in metaethics, Vol. 4, edited by R. Shafer-Landau. Oxford: Oxford University Press: 167-202.

Field, Hartry. 2009. Epistemology without metaphysics. Philosophical Studies 143: 249-290.

Finlay, S. 2005. Value and implicature. Philosophers' Imprint 5: 1-20.

Frápolli, M.J. and Villanueva, N. 2012. Minimal expressivism. Dialectica 66(4): 471-487.

Frápolli, M.J. and Villanueva, N. 2015. Expressivism, relativism, and the analytic equivalence test. Frontiers in Psychology and Language Sciences.

Frege, G. 1879. Begriffsschrift, a formula language modeled upon that of arithmetic, for pure thought. In From Frege to Gödel. A source book on mathematical logic, 1879-1931, edited by J. van Heijenoort. Cambridge, Mass.: Harvard University Press, 1967: 1-82.

Frege, G. 1880-1. Boole's logical calculus and the concept-script. In Posthumous Writings. Oxford: Basil Blackell, 1979: 9-46.

Frege, G. 1879-1891. Logic. In Posthumous Writings. Oxford: Basil Blackell, 1979: 1-8.

Frege, G. 1892. On sense and meaning. In Collected papers on Mathematics, Logic and Philosophy. Oxford: Basil Blackwell, 1984: 57-177.

Frege, G. 1914. Logic in mathematics. In Posthumous Writings. Oxford: Basil Blackell, 1979: 203-250.

Frege, G. 1918-19a. Thought. In Collected papers on Mathematics, Logic and Philosophy. Oxford: Basil Blackwell, 1984: 351-372.

Frege, G. 1918-19b. Negation. In Collected papers on Mathematics, Logic and Philosophy. Oxford: Basil Blackwell, 1984: 373-389.

Frege, G. 1923-6. Compound thoughts. In Collected papers on Mathematics, Logic and Philosophy. Oxford: Basil Blackwell, 1984: 390-406.

Frege, G. 1923. Logical generality. In Posthumous Writings. Oxford: Basil Blackwell, 1979: 258-262.

Frege, G. 1979. Posthumous Writings. Oxford: Basil Blackwell.

Frege, G. 1984. Collected papers on Mathematics, Logic and Philosophy, edited by B. McGuinness. Oxford: Basil Blackwell. 
Frege, G. 1884/1960. The Foundations of Mathematics. A logico-mathematical enquiry on the concept of number. New York: Harper Torchbook.

Grajner, M. 2015. Hybrid expressivism and epistemic justification. Philosophical Studies 172(9): 2349-2369.

Gibbard, A. 1990. Wise Choices, Apt Feelings: A Theory of Normative Judgment. Oxford: Oxford University Press and Cambridge, Mass.: Harvard University Press.

Gibbard, A. 2012. Meaning and Normativity. Oxford: Oxford University Press.

Lewis, David. 1996. Elusive knowledge. Australasian Journal of Philosophy 74: 549-567.

MacFarlane, J. 2014. Assessment Sensitivity. Relative Truth and its Applications. Oxford: Oxford University Press.

MacFarlane, J. 2007. Semantic minimalism and nonindexical contextualism. In Context-Sensitivity and Semantic Minimalism: New Essays on Semantics and Pragmatics, edited by G. Preyer and G. Peter. Oxford: Oxford University Press, 2007: 240-50.

Mates, B. 1952. Synonymity. In Semantics and the Philosophy of Language, edited by L. Linsky. Champaign, University of Illinois Press: 111-136.

Peirce, C. S. 1878. How to make our ideas clear. Popular Science Monthly 12: 286-302.

Ramsey, F.P. 1929. General propositions and causality. In Foundations. Essays in Philosophy, Logic, Mathematics, and Economics, edited by H. Mellor. London: Routledge and Kegan Paul, 1978: 133-51.

Salmon, N. U. 1986. Frege's puzzle. Cambridge, Mass., MIT Press.

Saul, J. 1998. The pragmatics of attitude ascription. Philosophical Studies 92: 363-389.

Searle, J. 1992. The Rediscovery of the Mind., MIT Press, Cambridge, MA.

Stanley, J. 2000. Context and logical form. Linguistics and Philosophy 23: 391 434.

Stojanovic, I. 2007. What Is Said: An Inquiry into Reference, Meaning and Content. VDM Verlag Dr. Müller.

Strandberg, C. 2012. A dual aspect account of moral language. Philosophy and Phenomenological Research 84: 87-120.

Recanati, F. 2010. Truth-Conditional Pragmatics. Oxford: Oxford University Press.

Recanati, F. 2002. Unarticulated constituents. Linguistics and Philosophy 25: 299345.

Williams, M. 2001. Problems of Knowledge. A critical introduction to epistemology. Oxford: Oxford University Press.

Yalcin, S. 2011. Nonfactualism about epistemic modality. In Epistemic Modality, edited by Andy Egan and B. Weatherson. Oxford: Oxford University Press. 